\title{
A Challenging Diagnosis of A Rare Association between Crohn's Disease, Behcet's Disease and Ankylosing Spondylodiscitis: Case Report And Review of the Literature
}

F. Haddar ${ }^{1 *}$, F. Bellouhou ${ }^{1}$, A. Ait Errami ${ }^{1}$, S. Oubaha ${ }^{2}$, K. Krati $^{1}$, Z. Samlani ${ }^{1}$

${ }^{1}$ Department of Gastroenterology, Mohammed VI University Hospital, Marrakech, Morocco

${ }^{2}$ Department of Physiology, Faculty of Medicine and Pharmacy at Cadi Ayyad University, Marrakech, Morocco

DOI: $10.36347 /$ sjmcr.2020.v08i02.014

| Received: 20.01.2020 | Accepted: 27.01.2020 | Published: 14.02.2020

*Corresponding author: F. Haddar

\section{Abstract}

Crohn's disease and Behçet's diseases are two multifactorial autoinflammatory diseases that share many clinical similarities. Their association is exceptional. We report a case of 33 year-old man monitored for Behcet's disease since 2014 hospitalized in our department for management of chronic abdominal pain revealing Crohn's disease. We focused on association of crohn's, Behçet's disease and ankylosing spondylodiscitis in order to showcase the diagnosis process and therapeutical specifics of this association.

Keywords: Behçet Disease, Crohn's Disease, Corticosteroids, Immunomodulatory Treatment, Infliximab. Copyright @ 2020: This is an open-access article distributed under the terms of the Creative Commons Attribution license which permits unrestricted use, distribution, and reproduction in any medium for non-commercial use (NonCommercial, or CC-BY-NC) provided the original author and source are credited.

\section{INTRODUCTION}

Behçet's disease (BD) was first described by Turkish dermatologist Hulusi Behçet in 1937 as a syndrome with oral and genital ulceration and ocular inflammation [1, 2]. It is a rare multisystemic inflammatory disease with an unknown etiology and a recurrent chronic pattern, characterized by recurrent oral and genital ulcers / ulcers with mucocutaneous, ocular, articular, vascular and / or gastrointestinal lesions. BD is included in both vasculitis, affecting vessels of all kinds and sizes, and in classifications of auto-inflammatory diseases [3]. Crohn's disease (CD) is a type of inflammatory bowel disease that can affect any part of the gastrointestinal tract, from the mouth to the anus. It often includes intestinal symptoms (abdominal pain, diarrhea, vomiting) and extraintestinal symptoms (fever, weight loss, anemia, rashes, arthritis, inflammation of the eye) [4]. When the gastrointestinal tract is involved, a differential diagnosis between $\mathrm{BD}$ and $\mathrm{CD}$ is very difficult. There are no pathognomonic examinations in the laboratory or endoscopic results of entero-Behçet, although few, large and deep ulcers with discrete margins are described as a typical endoscopic model. Recently, new diagnostic criteria and an index of disease activity have been proposed in the diagnosis of entero-Behçet [5]. The treatment of entero-Behçet is similar to that of $\mathrm{CD}$, including steroids, immunomodulators and biological agents (anti-tumor necrosis factor $\alpha$ antibody) [6, 7].
We report a case of a man hospitalized in our department for Crohn's and Behçet's diseases in order to present the diagnosis process and the therapeutic specificities of this association.

\section{Case Report}

Man of 33 years, chronic smoking at 20 PA. The patient has been under treatment and medical follow-up of Behçet's disease since 2014, his diagnosis was retained by the recurrence of bipolar aphtosis and a skin pseudo-folliculitis, anterior uveitis and positif pathergy test. The patient was treated with colchicine with good progress. The patient was admitted to abdominal pain aggravated by food and relieved by fasting, stool and gas, asthenia and weight loss of $14 \mathrm{~kg}$ in six months. The physical examination was normal. Biological tests highlight inflammatory anemia, with high levels of C-reactive protein $(165.30 \mathrm{mg} / 1)$. The patient was also tested for Tuberculosis infection: both sputum tests and interferon-gamma (IFN- $\gamma$ ) release assay were negative. Serologic marker of ASCA (antiSaccharomyces cerevisiae antibodies) and HLA B51 were both positive. The colonoscopy revealed diffuse ileitis with large ulcerations, inflammatory intervening mucosa and presence of ulcerable stenosis impassable to the endoscope (Figure-1). The enteroscopy revealed jejunal aphthous ulcerations without stenosis. Oesogastroduodenal fibroscopy was normal. Histological examination of the ileal biopsy revealed 
ulcerative ileitis and epithelioid granuloma compatible with Crohn's disease; there was any evidence of vasculitis, and histological examination of staged colon biopsies revealed inflammatory changes vasculoexudative of the colonic mucosa without any signs suggestive of ulcerative colitis. Duodenal biopsy and celiac serology were without abnormalities. MRI Enterography reveals a thickening of the jejunal and of the last ileal loop, the latter infiltrates the fat and the neighboring structures (sigmoid and bladder), and have deep cracks and ulcers (Figure-2). The diagnosis of Behçet's disease associated to Crohn's disease was made, and the patient was treated with first injected corticosteroids for 7 days then oral and colchicine. A positive evolution of the clinical and biological evolution of the two diseases was observed during the follow-up. During the 3rd month the patient presented a pain with bilateral functional impotence of the hip, the $\mathrm{X}$-ray of the pelvis objectified the presence of a bilateral fracture of the two femoral heads. Joint ultrasound showed bilateral effusion of the knees and hips, a joint puncture was sterile. A complement by an MRI of the hips (Figure-3) showed signs compatible with osteochondritis of the two femoral heads with coxaplana, without any osteolytic lesions and no image of abscess or joint effusion. Bone densitometry showed a respectively at the level of the spine and femur, a $\mathrm{T}$ score at $-3.1,-2.8$, a Z-score at $-2.2,-2.1$, with a total of $0.866 \mathrm{~g} / \mathrm{cm}^{2}$ and $0.699 \mathrm{~g} / \mathrm{cm}^{2}$ : very low for its age and sex. The diagnosis of ankylosing spondylodiscitis associated with the two previous diagnoses was probable. No surgical indication was asked. The decision was to stop corticosteroids immediately and to start treatment with anti-TNF (Infliximab). The evolution after one year of treatment was good.

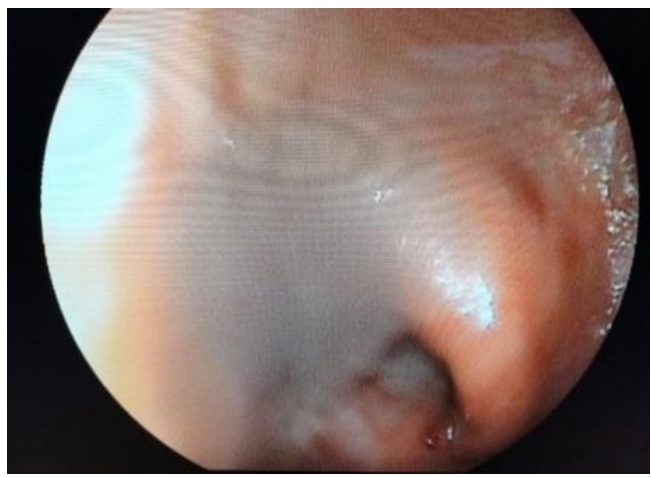

Fig-1: Endoscopic image revealing ileal stenosis with aphtoid ulcers

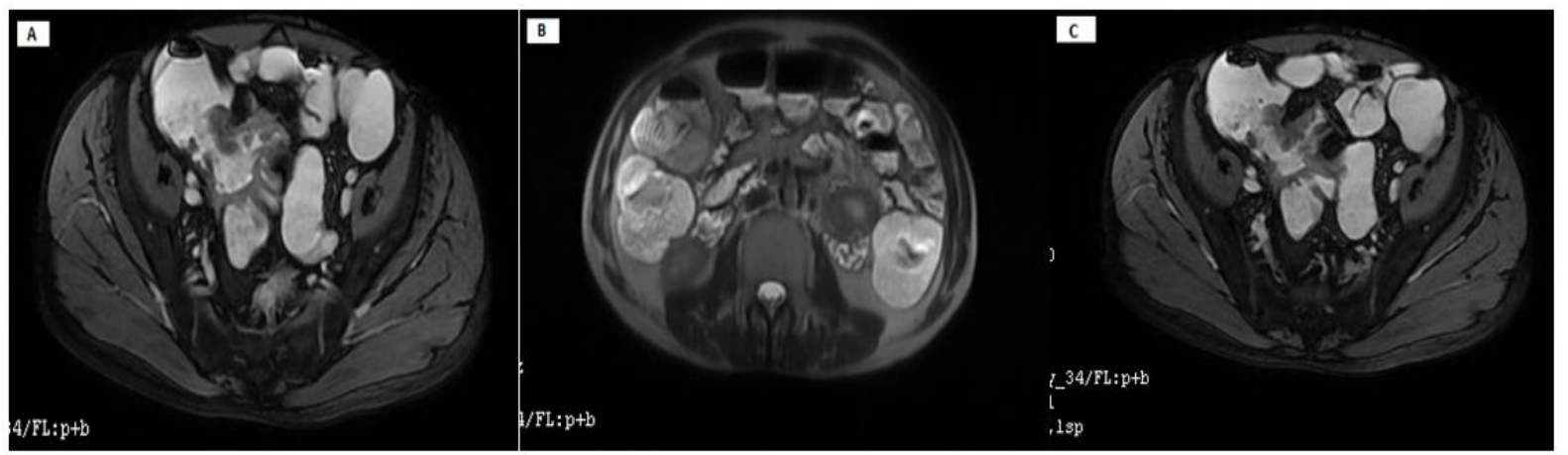

Fig-2: MRI Enterography reveals a thickening of the jejunal (B) and of the last ileal loop (A), the latter infiltrates the fat and the neighboring structures (sigmoid (C) and bladder), and have deep cracks and ulcers
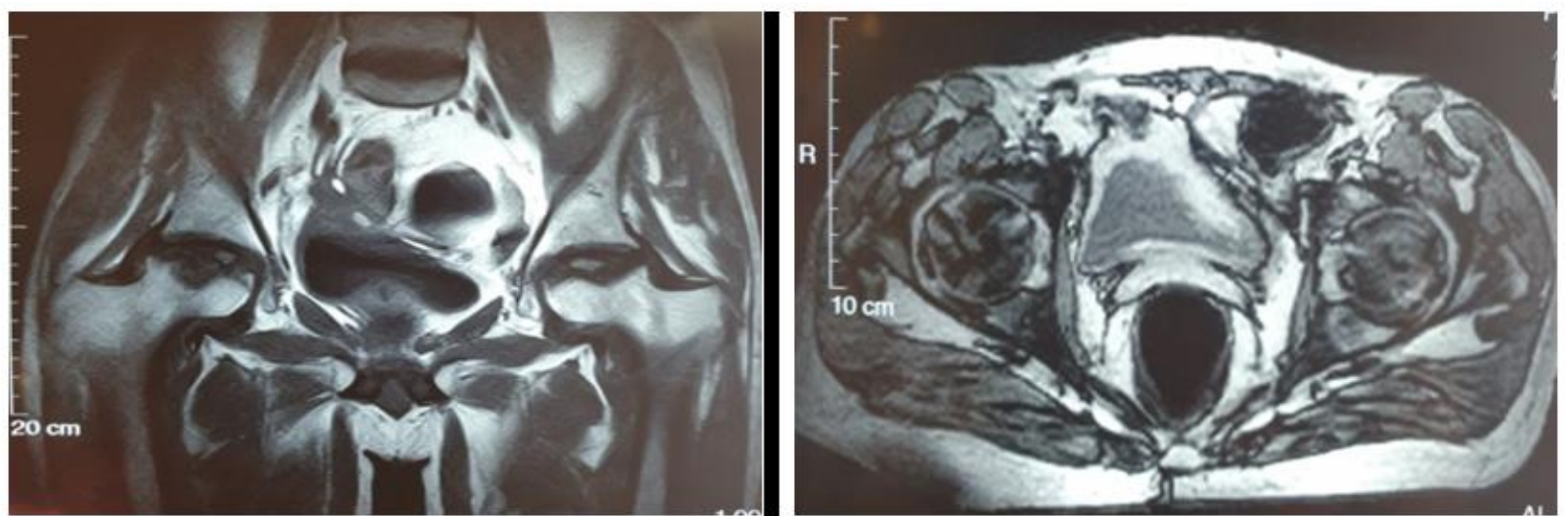

Fig-3: MRI axial and coronal sections of the hips reveals an osterochondritis of both femoral heads with coxaplana

\section{DISCUSSION}

Behçet's disease (BD) is a chronic, multisystemic and recurrent inflammatory disease 
characterized by recurrent oral ulcers, genital ulcers, uveitis and skin lesions. It also attacks other systems involving the musculoskeletal system, the blood vessels, the nervous system and the gastrointestinal tract. The disease is mainly found in Eastern Mediterranean countries and in eastern Asia, especially China $[8,9]$. The prevalence of entero-Behçet ranges from $0 \%$ to $60 \%$ of all BD patients with geographic and ethnic differences. The ileocecal region is the most commonly affected area and abdominal pain, diarrhea and gastrointestinal bleeding are common symptoms [10-12]. Entero-Behçet often mimics Crohn's disease (CD). Both diseases usually have an early age of onset, non-specific gastrointestinal symptoms, and similar extraintestinal manifestations [13]. Their clinical distinction is difficult. There are only a few comparative studies of differential diagnosis, wich were conducted in Korean patients [14]

$\mathrm{CD}$ is a complex disorder that mainly affects the small intestine and the colon. It is a transmural and inflammatory disease that can affect the entire gastrointestinal tract. Typical presentations include the presence of longitudinal ulcers with a cobblestone appearance, skip lesions, and the development of complications such as stenoses and fistulas. However, various extraintestinal manifestations of the disease, including oral and genital ulcers, erythema nodosum, uveitis and arthritis may also be observed [15,16]. Skin changes can be seen in $5 \%$ to $10 \%$ of patients. Erythema nodosum (5.6\% $-13.5 \%)$, pyoderma gangrenosum $(0.75 \%-0.15 \%)$ and acute neutrophilic dermatoses, also known as Sweet's disease, are among the major skin lesions. Other skin conditions include oral aphtous lesions, perianal lesions, large ulcers, fissures, fistulas and aseptic abscesses [17,18]. Pathergy positivity is extremely low in patients with $\mathrm{CD}$ compared to those with BD [19]. The most commun ocular conditions are uveitis, episcleritis, conjunctivitis and blepharitis. Non-granulomatous anterior uveitis may develop and recurrent episodes may result in permanent vision loss. Ocular complications are not associated with the severity. Additionally, retinal vasculitis, which is extremely rare, has been reported in the literature as a case study $[17,20]$.

In $\mathrm{BD}$, neutrophilic infiltration, lymphocyte aggregation of surrounding vessels and vascular proliferation were observed in biopsy samples of oral and genital ulcers. Infiltration predominantly neutrophils, abscess formation, and vasculitis-related changes may be present in the skin lesions. Aggregation of lymphocytes, neutrophils and eosinophils, as well as edema and leukocytoclasia occur in the pathergy test site within the first 12 hours. In the presence of significant vessel involvement such as aortic involvement, rupture or loss of medial elastic fibers may be observed, while vaso vasorum proliferation and lymphocytic infiltration of surrounding tissues may develop. [21, 22]. Lymphocytic and necrotizing vasculitidis are other conditions involving the pulmonary arteries, the veins and the septal capillaries. In addition, transmural necrosis and aneurysms of the great vessels and pulmonary arteries may occur. Despite the nonspecific nature, perivascular lymphhocyte/ plasma cell infiltration and myelin loss of parenchymal CNS lesions may occur [22].

Entero-Behçet's disease may lead to mesenteric vasculitis with ischemia or necrosis of the intestines. Ulcer specimens often show non-specific profiles, including fibrinopurulent exudates and necrotic debris in active ulcers and transmural fibrosis in chronic ulcers. Inflammation of the lumen to the serosa is present in the perforated site with mural necrosis. Vasculitic changes secondary to the inflamed surrounding tissue and thrombus formation in small vessels, including both arteries and veins, are other critical manifestations. Lymphoid follicles can be observed due to mucosal erosion in some cases. The differential diagnosis of these lesions, which are histopathologically suggestive of $\mathrm{CD}$, is highly challenging $[23,24]$.

The histopathological features of $\mathrm{CD}$ are discontinuous cryptic architectural abnormalities, the preservation of mucin at active sites, discontinous inflammation, focal cryptitis, and epithelioid ganulomas. Granulomas in histological sections are key features of $\mathrm{CD}$, but are not necessary for diagnosis. In the submucosa, fibromuscular obliteration, nerve fibers hyperplasia and transmural lymphoid aggregates are observed. Transmucosal increase in lamina propria cellularity and neutrophils are an indicator of disease activity [25].

Both $\mathrm{BD}$ and $\mathrm{CD}$ may present transmural enteritis and colitis. Longitudinal ulcers, pavement appearance and anorectal fistula are common signs of Crohn's colitis. The presence of granulomas in biopsy specimens indicates $\mathrm{CD}$, whereas vasculitis suggests $\mathrm{BD}[13]$.

Although there is no specific diagnostic test for $\mathrm{BD}$, sets of diagnostic criteria described at different times are available. The the International Study Group (ISG) criteria, defined in 1990, are the most commonly used criteria for the diagnosis of BD (table 1) [22]. In addition, some cases of CD meet these criteria. These criteria are based on the most frequent clinical signs of BD. In this case, our patient is suffering from behçet disease according to criteria of international classification of behçet disease with associated crohn disease according to endoscopic and histological data.

Several diagnostic and classification criteria for $\mathrm{CD}$ have been proposed [26, 27]. The location and appearance of the lesions are important for the diagnosis of CD. According to the Vienna [28] and 
Montreal [29] classifications, the diagnosis of $\mathrm{CD}$ is based on three variables : 1) age at diagnosis; (2) disease location; and (3) disease behavior. Lennard Jones's criteria are based on endoscopic, surgical / histopathological, radiological and clinical findings [30]. The Copenhagen criteria include histopathological confirmation of CD disease [31] (Table-1). The diagnosis is usually based on the patient's history, physical examination, laboratory results, imaging studies, and endoscopic findings associated with the histopathological examination. Patients with BD, particularly those with intestinal involvement, may be misdiagnosed and mismanaged as $\mathrm{CD}$ by clinicians with insufficient experience and knowledge on BD.

Since BD is a multisystemic disorder, effective management of the disease requires a multidisciplinary approach. Although the disease should be primarily managed by a rheumatologist, consultation is provided by a dermatologist, a neurologist, a gastroenterologist and a cardiovascular surgeon, if necessary. The disease is inflammatory. therefore, immunosuppressive and immunomodulatory agents are first-line treatments. Due to the limited number of randomized controlled clinical trials, management usually depends on the clinical experience of the treating physician. In 2008, the European League Against Rheumatism (EULAR) published a recommendation for the management of BD [32].

The management of patients with BD is based on the presence of organ involvement and disease severity. Colchicine is a widely used treatment for BD. It is used for the management of mucocutaneous and musculoskeletal findings. Corticosteroids and azathioprine can be combined in patients who does not are respond to colchicine treatment and who have ocular, vascular, neurological, or intestinal involvement. Cyclosporine and interferon alfa are immunosuppressive agents used in the management of refractory uveitis and retinal vasculitis. A small number or patients with an inadequate response may require mycophenolate mofetil and infliximab. Currently, these agents are used experimentally in the management of vascular involvement. In addition, cyclophosphamide is an effective immunosuppressive agent that increase side effects in patients with arterial, venous or neurological involvement who are refractory to other agents. Other agents that are preferred in unresponsive arthritis with a tendency to chronicity include methotrexate and sulfasalazine. The latter is the most widely preferred agent in patients with entero-Behçet disease after corticosteroids and azathioprine. However, there are no randomized controlled clinical trials in patients with BD. Observational studies and case series have shown that steroids, mesalazine, azathioprine and sulfasalazine could be used in the treatment of inflammatory bowel disease. Recently, experience with the use of anti-TNF agents has increased and some patients respond well to treatment. In addition to immunosuppressants, antiaggregants and anticoagulants may be initiated in patients with venous or neurologic involvement. However, no consensus on the use of antiaggregants and anticoagulants has been achieved yet, due to the low embolization tendency BD-associated thrombosis and the high risk of bleeding secondary to arterial aneurysms. In clinical practice, these agents are prescribed in patients with a low risk of bleeding [32, 33].

Corticosteroids have been used in the management of $\mathrm{CD}$ for more than five decades. Corticosteroids are the most effective therapeutic agents to relieve exacerbations of the disease. They exert remarkable effects on the suppression of proinflammatory cytokines and active lymphocytes and on the inhibition of inflammatory processes of the intestinal lamina propria. Although corticosteroids are more effective at higher concentrations, treatmentrelated side effects may increase. Treatment with prednisolone is usually initiated at $40-60 \mathrm{mg} /$ day and gradually reduced. About $48 \%$ to $58 \%$ of patients achieve complete remission, while $26 \%$ to $32 \%$ achieve partial remission after 30 days of treatment. About $16 \%$ to $20 \%$ of patients do not respond. Six mercaptopurine and its pro-drug azathioprine are the most commonly used agents in patients not responding to corticosteroids and maintenance therapy. Methotrexate is an alternative agent in patients who are intolerant or unresponsive to these agents. On the other hand, controversial data are available on the efficacy of 5-aminosalicylic acid (5ASA) preparations. In several meta-analyzes, mesalazine at $4 \mathrm{~g} /$ day significantly reduced in patients with mild to moderate activity. All of these agents are frequently prescribed because of their low side effects potential $[34,35]$. Anti-TNF agents such as infliximab, adalimumab and certolizumab pegol may be used in refractory patients with relapsing disease. Metaanalyzes have shown that anti-TNF agents are effective as induction and maintenance therapy in CD patients with fistula [36]. Surgery is indicated in patients with perianal involvement, fistulas, fissures, and intraabdominal abscesses.

The approaches to medical and surgical management of CD and enter-Behçet disease BD are similar. Recently, a retrospective case series with longterm outcomes for both diseases has been reported [14]. Ten year-follow-up data after diagnosis showed no significant difference in the need for surgery between the study groups with $\mathrm{CD}$ and intestinal BD. However, $\mathrm{CD}$ patients required a higher dose of corticosteroids and immunosuppressive agents. The doses of biological agents were also higher in $\mathrm{CD}$ patients compared to patients with intestinal BD (14.2\% vs $1.4 \%)$. Based on these results, long-term prognosis appears to be similar in patients with $\mathrm{CD}$ and intestinal $\mathrm{BD}$ [37]. 
Table-1: Diagnostic criteria for Behçet's disease and Crohn's disease

\begin{tabular}{|c|c|c|c|c|}
\hline & \multirow[b]{2}{*}{$\begin{array}{l}\text { International } \\
\text { Study Group } \\
\text { Diagnostic } \\
\text { Criteria for } \\
\text { Behçet's } \\
\text { disease [22] }\end{array}$} & \multicolumn{3}{|c|}{ Proposed diagnostic criteria for Crohn's disease } \\
\hline & & Japan Criteria [27] & $\begin{array}{l}\text { Lennard-Jones Criteria } \\
{[30]}\end{array}$ & Copenhagen Criteria [31] \\
\hline $\begin{array}{l}\text { Major } \\
\text { findings }\end{array}$ & $\begin{array}{l}\text { Recurrent oral } \\
\text { ulcerations }\end{array}$ & $\begin{array}{l}\text { A: Longitudinal } \\
\text { ulcer B: } \\
\text { Cobblestone-like } \\
\text { appearance C: } \\
\text { Noncaseating } \\
\text { epithelioid cell } \\
\text { granuloma }\end{array}$ & \multirow{2}{*}{$\begin{array}{l}\text { Typical diarrhea history } \\
\text { for at least } 2 \text { mo; } 1 \\
\text { Radiological features of } \\
\text { CD: segmental } \\
\text { distribution, deep } \\
\text { ulcerations or } \\
\text { cobblestone pattern, } \\
\text { thickened bowel wall, } \\
\text { coarse mucosal relief, } \\
\text { stenotic segments and } \\
\text { fistulae; } 2 \text { Macroscopic } \\
\text { diagnosis by } \\
\text { endoscopy: patchy } \\
\text { penetrating lesions, } \\
\text { fissuring and strictures } \\
3 \text { Fistulas and/or } \\
\text { abscesses with typical } \\
\text { intestinal disease }\end{array}$} & \multirow{2}{*}{$\begin{array}{l}\text { 1 History of abdominal } \\
\text { pain, weight loss and/or } \\
\text { diarrhea for more than } 3 \\
\text { mo } 2 \text { Characteristic } \\
\text { endoscopic findings of } \\
\text { ulceration (aphtous } \\
\text { lesions, snail track } \\
\text { ulceration) or cobble } \\
\text { stoning or radiological } \\
\text { features of stricture or } \\
\text { cobble stoning } 3 \\
\text { Histopathology } \\
\text { consistent with Crohn's } \\
\text { disease (epitheloid } \\
\text { granuloma of Langerhans } \\
\text { type or transmural } \\
\text { discontinuous focal or } \\
\text { patchy inflammation) } 4 \\
\text { Fistula and/or abscess in } \\
\text { relation to affected bowel } \\
\text { segments }\end{array}$} \\
\hline $\begin{array}{l}\text { Minor } \\
\text { findings }\end{array}$ & $\begin{array}{l}\text { Recurrent genital } \\
\text { ulcerations Eye } \\
\text { lesions Skin } \\
\text { lesions Positive } \\
\text { pathergy test }\end{array}$ & $\begin{array}{l}\text { (1) Irregular-shaped } \\
\text { and/or quasi-circular } \\
\text { ulcers or aphthous } \\
\text { ulcerations found } \\
\text { extensively in the } \\
\text { gastrointestinal tract } \\
\text { (2) Characteristic } \\
\text { perianal lesions (3) } \\
\text { Characteristic gastric } \\
\text { and/or duodenal } \\
\text { lesions }\end{array}$ & & \\
\hline Definite & $\begin{array}{l}\text { Major finding plus } \\
\text { two minor } \\
\text { findings }\end{array}$ & $\begin{array}{l}1 \text { Major finding A or } \\
\text { B } 2 \text { Major finding C, } \\
\text { with minor finding } \\
\text { (1) or (2) } 3 \text { All } \\
\text { minor findings (1), } \\
(2) \text {, and (3) }\end{array}$ & $\begin{array}{l}\text { Positive findings or one } \\
\text { positive plus the finding } \\
\text { of granuloma }\end{array}$ & $\begin{array}{l}\text { At least two of the criteria } \\
\text { present }\end{array}$ \\
\hline
\end{tabular}

\section{Conclusion}

CD mainly concerns the gastrointestinal system and may present with various extra-intestinal signs and symptoms. However, BD is a condition or syndrome that manifests itself as multisystemic. The gastrointestinal tract is also one of the main sites of involvement in these patients. Both diseases have a real overlap, affecting the gastrointestinal tract. In addition, both conditions share similar characteristics with respect to age of onset, gender, and biomarkers of inflammation such as erythrocyte sedimentation rate and C-reactive protein. Despite these similarities, immunopathogenesis, genetic factors and regional distribution are very different. Although both diseases involve similar systems, they have distinct histopathological features.

\section{REFERENCES}

1. Hatemi I, Hatemi G, Celik AF. Gastrointestinal Involvement in Behçet Disease. Rheumatic diseases clinics of North America. 2018 Feb;44(1):45-64.

2. Behçet H. Rezidivierende aphthose, durch ein virus verusachte geschwure am auge und an den genitalien. Dermatol Wochenschr. 1937;105:1152157.

3. Chen Y, Liu W, Zou J, Luo D, Cai J, Guan J. Intestinal pathological changes in Behcet's disease: a clinical retrospective study. Fudan University Journal of Medical Sciences. 2017 Jan 1;44(4):493-497.

4. Sakane T, Takeno M, Suzuki N, Inaba G. Behçet's disease. New England Journal of Medicine. 1999 Oct 21;341(17):1284-91.

5. Cheon JH, Kim ES, Shin SJ, Kim TI, Lee KM, Kim SW, Kim JS, Kim YS, Choi CH, Ye BD, Yang SK. Development and validation of novel diagnostic criteria for intestinal Behçet's disease in Korean patients with ileocolonic ulcers. American Journal of Gastroenterology. 2009 Oct 1;104(10):2492-9.

6. Hatemi I, Esatoglu SN, Hatemi G, Erzin Y, Yazici $\mathrm{H}$, Celik AF. Characteristics, treatment, and longterm outcome of gastrointestinal involvement in Behcet's syndrome: a strobe-compliant observational study from a dedicated multidisciplinary center. Medicine. 2016 Apr;95(16):e3348. 
7. Valenti S, Gallizzi R, De Vivo D, Romano C. Intestinal Behçet and Crohn's disease: two sides of the same coin. Pediatric Rheumatology. 2017 Dec;15(1):33.

8. Kaklamani VG, Vaiopoulos G, Kaklamanis PG. Behçet's disease. Semin Arthritis Rheum. 1998; 27: 197-217.

9. Sakane T, Takeno M, Suzuki N, Inaba G. Behçet's disease. N Engl J Med. 1999; 341: 1284-91.

10. Kasahara Y, Tanaka S, Nishino M, Umemura H, Shiraha S, Kuyama T. Intestinal involvement in Behçet's disease: Review of 136 surgical cases in the Japanese literature. Dis Colon Rectum. 1981; 24:103-106.

11. Ideguchi H, Suda A, Takeno M, Miyagi R, Ueda A, Ohno S, Ishigatsubo Y. Gastrointestinal manifestations of Behçet's disease in Japan: a study of 43 patients. Rheumatology International. 2014 Jun 1;34(6):851-6.

12. Ebert EC. Gastrointestinal manifestations of Behçet's disease. Digestive diseases and sciences. 2009 Feb 1;54(2):201.

13. Grigg EL, Kane S, Katz S. Mimicry and deception in inflammatory bowel disease and intestinal behçet disease. Gastroenterol Hepatol (N Y) 2012; 8: 103-12.

14. Zhang T, Hong L, Wang Z, Fan R, Zhang M, Lin Y, Cheng M, Zhou X, Sun P, Lin X, Zhong J. Comparison between intestinal Behçet's disease and Crohn's disease in characteristics of symptom, endoscopy, and radiology. Gastroenterology research and practice. 2017; 10:1155-1162.

15. Amarapurkar DN, Patel ND, Rane PS. Diagnosis of Crohn's disease in India where tuberculosis is widely prevalent. World J Gastroenterol. 2008; 14: 741-6.

16. Baumgart DC, Sandborn WJ. Crohn's disease. Lancet. 2012; 380: 1590-1605.

17. Larsen S, Bendtzen K, Nielsen OH. Extraintestinal manifestations of inflammatory bowel disease: epidemiology, diagnosis, and management. Ann Med. 2010; 42: 97-114.

18. Ardizzone S, Puttini PS, Cassinotti A, Porro GB. Extraintestinal manifestations of inflammatory bowel disease. Dig Liver Dis. 2008; 40 Suppl 2:S253-S259.

19. Hatemi I, Hatemi G, Celik AF, Melikoglu M, Arzuhal N, Mat C, Ozyazgan Y, Yazici H. Frequency of pathergy phenomenon and other features of Behçet's syndrome among patients with inflammatory bowel disease. Clin Exp Rheumatol. 2008; 26: S91-S95.

20. Yilmaz S, Aydemir E, Maden A, Unsal B. The prevalence of ocular involvement in patients with inflammatory bowel disease. International journal of colorectal disease. 2007 Sep 1;22(9):1027-1030.

21. Hamuryudan V, Melikoğlu M. Vascular Disease in Behçet's Syndrome. 1st ed. In: Yazici Y, Yazici $\mathrm{H}$, editors. Behçet's Syndrome (NY): Springer; 2010; 115-135.
22. Chun SI, Su WD, Lee S. Histopathologic study of cutaneous lesions in Behçet's syndrome. The Journal of dermatology. 1990 Jun;17(6):333-41.

23. Matsumoto T, Uekusa T, Fukuda Y. VasculoBehçet's disease: a pathologic study of eight cases. Human pathology. 1991 Jan 1;22(1):45-51.

24. Demirkesen C, Oz B, Göksal S. Behçet's Disease: Pathology. 1st ed. In: Yazici Y, Yazici H, editors. Behçet's Syndrome (NY): Springer; 2010; 215 243.

25. Geboes K. What histologic features best differentiate Crohn's disease from ulcerative colitis? Inflamm Bowel Dis. 2008; 14 Suppl 2:S168-S169.

26. Vind I, Riis L, Jess T, Knudsen E, Pedersen N, Elkjær M, Andersen IB, Wewer V, Nørregaard P, Moesgaard F, Bendtsen F. Increasing incidences of inflammatory bowel disease and decreasing surgery rates in Copenhagen City and County, 2003-2005: a population-based study from the Danish Crohn colitis database. American Journal of Gastroenterology. 2006 Jun 1;101(6):1274-82.

27. Matsui T, Hirai F, Hisabe T. Proposed diagnostic criteria for Crohn's disease. Annual reports of the research group of intractable inflammatory bowel disease subsidized by the Ministry of Health, Labour, and Welfare of Japan, Tokyo, Japan. Behçet's Syndrome (NY): Springer; 2011:52-54.

28. Gasche C, Scholmerich J, Brynskov J, D'Haens G, Hanauer SB, Irvine JE, Jewell DP, Rachmilewitz D, Sachar DB, Sandborn WJ, Sutherland LR. A simple classification of Crohn's disease: report of the Working Party for the World Congresses of Gastroenterology, Vienna 1998. Inflammatory bowel diseases. 2000 Feb 1;6(1):8-15.

29. Silverberg MS, Satsangi J, Ahmad T, Arnott ID, Bernstein CN, Brant SR, Caprilli R, Colombel JF, Gasche C, Geboes K, Jewell DP. Toward an integrated clinical, molecular and serological classification of inflammatory bowel disease: report of a Working Party of the 2005 Montreal World Congress of Gastroenterology. Canadian Journal of Gastroenterology and Hepatology. 2005;19(Suppl A):5A-36A.

30. Lennard-Jones JE. Classification of inflammatory bowel disease. Scandinavian Journal of Gastroenterology. 1989 Jan 1;24(sup170):2-6.

31. Vind I, Riis L, Jess T, Knudsen E, Pedersen N, Elkjær M, Andersen IB, Wewer V, Nørregaard P, Moesgaard F, Bendtsen F. Increasing incidences of inflammatory bowel disease and decreasing surgery rates in Copenhagen City and County, 2003-2005: a population-based study from the Danish Crohn colitis database. American Journal of Gastroenterology. 2006 Jun 1;101(6):1274-82.

32. Hatemi G, Silman A, Bang D, Bodaghi B, Chamberlain AM, Gul A, Houman MH, Kötter I, Olivieri I, Salvarani C, et al. EULAR recommendations for the management of Behçet disease. Ann Rheum Dis. 2008; 67: 1656-1662. 
33. Arida A, Fragiadaki K, Giavri E, Sfikakis PP. Anti-TNF agents for Behçet's disease: analysis of published data on 369 patients. Semin Arthritis Rheum. 2011; 41: 61-70.

34. Girardin M, Manz M, Manser C, Biedermann L, Wanner R, Frei P, Safroneeva E, Mottet C, Rogler G, Schoepfer AM. First-line therapies in inflammatory bowel disease. Digestion. 2012; 86 Suppl 1: 6-10.

35. Ueno F, Matsui T, Matsumoto T, Matsuoka K, Watanabe M, Hibi T. Evidence-based clinical practice guidelines for Crohn's disease, integrated with formal consensus of experts in Japan. J Gastroenterol. 2013; 48: 31-72.

36. Kawalec P, Mikrut A, Wiśniewska N, Pilc A. Tumor necrosis factor- $\alpha$ antibodies (infliximab, adalimumab and certolizumab) in Crohn's disease: systematic review and meta-analysis. Arch Med Sci. 2013; 9: 765-779.

37. Jung YS, Cheon JH, Park SJ, Hong SP, Kim TI, Kim WH. Long-term clinical outcomes of Crohn's disease and intestinal Behcet's disease. Inflamm Bowel Dis. 2013; 19: 99-105. 